\title{
The Effect of Domestic Preparation of Some Potato Products on Acrylamide Content
}

\author{
Joanna Michalak • Elżbieta Gujska • Joanna Klepacka
}

Published online: 19 August 2011

(C) The Author(s) 2011. This article is published with open access at Springerlink.com

\begin{abstract}
The influence that food heating has on the concentration of acrylamide in home-cooked potato dishes prepared by high-temperature, such as pan-frying, deepfrying, roasting and microwave heating was analyzed. The experiment was performed with commercially available deep-frozen par-fried French fries and deep-frozen par-fried potato products other than French fries (cubes, wedges, noisettes, pancakes). Acrylamide was found in all deepfrozen par-fried French fries and other deep-frozen par-fried potato products before domestic preparation. The mean level of acrylamide content in all frozen potato products before preparation was found to be $322 \mu \mathrm{g} / \mathrm{kg}$. Potato products were then prepared at $180{ }^{\circ} \mathrm{C}$ for $3 \mathrm{~min}$ and at $220{ }^{\circ} \mathrm{C}$ for $10 \mathrm{~min}$. After domestic preparation (roasting, pan-frying, deep-frying and microwave heating) it was found that the level of acrylamide in all products increased. Acrylamide content in the analyzed samples significantly increased as the temperature and time of processing increased. The statistical analysis showed significant differences $(P<0.05)$ for acrylamide content as a function of food preparation. The level of acrylamide increased with the increased heating temperature and heating time. Additionally, the preparation method of roasting was significantly lower in acrylamide content $(P<0.05)$ than the preparation method of microwaving although both preparation methods used the same conditions (time and temperature). These results suggest that microwaving might be more favourable to the formation of acrylamide than conventional heating methods, such as roasting.
\end{abstract}

J. Michalak $(\bowtie) \cdot$ E. Gujska $\cdot$ J. Klepacka

Food Science Department, University of Warmia and Mazury,

ul. Heweliusza 6,

10-957 Olsztyn, Poland

e-mail: seniutaj@uwm.edu.pl
Keywords Acrylamide · HPLC · Potato products · Frying · Roasting $\cdot$ Microwaving $\cdot$ Domestic preparation

\section{Introduction}

Acrylamide is a probable human carcinogen molecule. In 1994, the International Agency for Research on Cancer classified industrial chemical acrylamide as a probable human carcinogen based on its carcinogenic action in rodents [1]. It is also a well-known neurotoxin [2]. In 2002, acrylamide was detected at high concentrations in heatprocessed foods. During heating the Maillard reaction takes place, affording food attractive sensory properties. However, various hazardous compounds formed at the same time, such as acrylamide. It is a fact that acrylamide can form during intense heat treatments as a consequence of Maillard-type reactions between free amino acids, particularly asparagine and reducing sugars such as glucose and fructose. Maximum limits for acrylamide in food have not been established, although the WHO guideline for acrylamide in drinking water is $0.5 \mu \mathrm{g} / \mathrm{kg}[2,3]$.

In the meantime, scientists have identified different factors affecting the formation of acrylamide in food. It can be assumed that processing and food preparation, as well as the raw materials used can cause the formation of acrylamide. As acrylamide has not been detected in unheated or boiled foods, it is considered to be formed during heating at high temperatures above $120^{\circ} \mathrm{C}$. This fact has been attributed to the higher temperatures reached in Maillard reactions required for acrylamide formation. The Maillard reaction takes place during frying and roasting. It has been shown that the type and conditions of preparation of food (pre-treatments, temperatures and times) have an important influence on the content of acrylamide. The 
literature suggests that there may be ways to reduce or prevent acrylamide formation by changing the production and preparation methods for commercially manufactured and domestic food. This may also occur during cooking in households, restaurants and catering enterprises. Modifying the cooking process may be able to reduce the amount of acrylamide in food [3-10].

Acrylamide has been detected in French fries, potato chips, crisps, bread, crisp bread, breakfast cereal, cookies, biscuits, crackers, roasted coffee and other products at levels up to $2,000 \mu \mathrm{g} / \mathrm{kg}$. Highly-strongly heated potato products such as French fries, potato chips, crisps and hash browns have been found to be major contributors of acrylamide in the diet. With a yearly worldwide production of about 330 million tons, the potato represents one of the world's major staple food crops. Deep-frying is one of the most popular food preparation methods, both industrially and at home [11, 12]. The purpose of the study was to examine the concentration of acrylamide in home-cooked potato dishes prepared by high-temperature cooking, such as pan-frying, deep-frying, roasting and microwave heating.

\section{Materials and Methods}

\section{Materials}

The experiment was performed with commercially available deep-frozen par-fried French fries before final domestic preparation. Three variants (crinkle, thick-cut, shoestring) and four deep-frozen par-fried potato products other than French fries (potato cubes, potato wedges, potato pancakes, and potato noisettes) were obtained from a local retailer. Directly after purchasing, all the different types of potato products were prepared by pan-frying, deep-frying ( 3 min at $180^{\circ} \mathrm{C}$ ), roasting and microwaving $\left(10 \mathrm{~min}\right.$ at $\left.220^{\circ} \mathrm{C}\right)$. Fresh sunflower oil was used in all experiments. The deep-frying of all potato products was performed in a domestic scale fryer (2 $\mathrm{L}$ of oil). $200 \mathrm{~g}$ portions of products were fried in hot oil. Oil temperature during frying was monitored by immersing a thermocouple in the fryer. Pan-frying was performed in saucepan using $100 \mathrm{~g}$ portions of par-fried products fried in $100 \mathrm{ml}$ of hot oil. The roasting of potato products was performed in a domestic oven. Microwaving was conducted in a domestic microwave oven. The temperature and operating power of the microwave were set at $220{ }^{\circ} \mathrm{C}$ at $700 \mathrm{~W}$ for $10 \mathrm{~min}$. The temperature and heating time of the heating medium in all domestic appliances were measured during the treatments. The measurements were performed using an automatic temperature control system for domestic appliances. Finally, the products were cooled to $20{ }^{\circ} \mathrm{C}$ at room temperature for about $30 \mathrm{~min}$. All samples were ground in a blender and stored at $4{ }^{\circ} \mathrm{C}$ before analysis. Table 1 shows the main characteristics of these potato products used in this study.

\section{Methods}

The average composition of potato products as reported in the respective labels is shown in Table 1 . The dry mater contents of products were determined according to an official AOAC method [13]. Briefly, $5 \mathrm{~g}$ of homogenized products were mixed with calcined sea sand and placed in an oven at $105{ }^{\circ} \mathrm{C}$ until a constant weight was obtained.

The acrylamide contents in the samples were determined by RP - HPLC methods with minor changes [14-18]. The analyses were performed using Shimadzu LC-20AD series for HPLC equipped with a UV - Vis $190-600 \mathrm{~nm}$ diode array detector (DAD, Shimadzu) set at $200 \mathrm{~nm}$, a vacuum degasser, binary pumps, a thermostated autosampler and a temperature-controlled column oven. The column used was a C18, $4.0 \mathrm{~mm}$ guard column and a Synergi $4 \mu$ Hydro-RP 80 A $250 \times 4.6 \mathrm{~mm}$ LC column from Phenomenex (Torrance, $\mathrm{CA})$. The operating conditions were as follows: the mobile phase was an isocratic mixture of $5 \mathrm{mM}$ heptasulfonic; flow rate, $1.0 \mathrm{ml} / \mathrm{min}$; injection volume, $100 \mu \mathrm{l}$; column temperature $25{ }^{\circ} \mathrm{C}$; autosampler temperature, $4^{\circ} \mathrm{C}$. Acrylamide elutes near 8-9 min. The total time from one injection to the next injection was $30 \mathrm{~min}$. Peak identification was based on the retention time, by comparison of the ratio of UV spectra with that of a standard commercial compound. The preparation of the samples was based on the method described by researchers with minor changes [18-22]. The sample preparation procedure included the extraction of acrylamide with $80 \%$ methanol in water, de-fatting with hexane, freezing to $-18^{\circ} \mathrm{C}$ and clean-up by SPE with HLB $200 \mathrm{mg}$ cartridges. Four grams of each food sample were homogenized with $20 \mathrm{ml}$ of $80 \%$ methanol and shaken in a thermostated water bath set at $60{ }^{\circ} \mathrm{C}$ for $60 \mathrm{~min}$. After the extraction of acrylamide, the samples were filtered through filter-paper to complete the defatting process. A portion $(20 \mathrm{ml})$ of hexane was added and shaken for $10 \mathrm{~min}$. The upper hexane layer was removed and the de-fatting step was then repeated. Five millilitres of aqueous solution was transferred to centrifuge tubes and frozen to $-18{ }^{\circ} \mathrm{C}$ for $24 \mathrm{~h}$ and subsequently centrifuged at $5,000 \mathrm{rpm}(3,000 \mathrm{~g})$ for $10 \mathrm{~min}$. The clear supernatant was then cleaned up with Oasis HLB SPE cartridges $(6 \mathrm{ml}$, $200 \mathrm{mg}$ ) purchased from Waters (Milford, MA). The final sample was filtered through a $0.45 \mu \mathrm{m}$ nylon syringe filter and analyzed by RP - HPLC. The acrylamide concentrations are expressed in $\mu \mathrm{g} / \mathrm{kg}$. The method was validated by defining the linearity, LOD and repeatability, precision and recovery. The linearity of the standard curve was expressed in terms of the correlation coefficient $\left(\mathrm{R}^{2}\right)$, the plot of the integrated peak area (\% of UV spectra) vs. the concentration of the standard. A linear regression equation $(\mathrm{y}=0.0018 \mathrm{x}-0.0299)$ was 
Table 1 Average composition of potato products as reported on their respective labels

\begin{tabular}{|c|c|c|c|c|c|c|c|}
\hline Product variety & Characteristic & $n$ & Energy (kcal/100 g) & Protein $(g / 100 g)$ & Carbohydrate $(\mathrm{g} / 100 \mathrm{~g})$ & Fat $(g / 100 g)$ & $\mathrm{DM}^{\mathrm{a}}(\%)$ \\
\hline \multirow[t]{14}{*}{ French fries } & \multirow[t]{6}{*}{ Crinkle } & \multirow[t]{6}{*}{5} & 141 & 1.8 & 23.8 & 4.3 & 34 \\
\hline & & & 174 & 3.0 & 29.0 & 5.5 & 39 \\
\hline & & & 141 & 2.4 & 22.7 & 4.5 & 34 \\
\hline & & & 145 & 2.5 & 22.5 & 5.0 & 34 \\
\hline & & & 172 & 2.5 & 28.0 & 5.5 & 38 \\
\hline & & & $156^{\mathrm{b}}$ & $2.4^{\mathrm{b}}$ & $25.2^{\mathrm{b}}$ & $5.0^{\mathrm{b}}$ & $36^{\mathrm{b}}$ \\
\hline & \multirow[t]{4}{*}{ Thick-cut, } & \multirow[t]{4}{*}{3} & 135 & 2.5 & 21.0 & 4.5 & 31 \\
\hline & & & 135 & 3.0 & 23.0 & 4.0 & 31 \\
\hline & & & 141 & 2.0 & 23.0 & 5.0 & 33 \\
\hline & & & $137^{\mathrm{b}}$ & $2.5^{\mathrm{b}}$ & $22.3^{\mathrm{b}}$ & $4.5^{\mathrm{b}}$ & $32^{\mathrm{b}}$ \\
\hline & \multirow[t]{4}{*}{ Shoestring } & \multirow[t]{4}{*}{3} & 141 & 2.4 & 22.7 & 4.5 & 33 \\
\hline & & & 135 & 2.0 & 22.0 & 5.0 & 31 \\
\hline & & & 141 & 2.4 & 22.7 & 4.5 & 32 \\
\hline & & & $139^{\mathrm{b}}$ & $2.3^{\mathrm{b}}$ & $22.5^{\mathrm{b}}$ & $4.7^{\mathrm{b}}$ & $32^{\mathrm{b}}$ \\
\hline \multirow[t]{4}{*}{ Other potato products } & Cubes & $3^{\mathrm{c}}$ & 158 & 2.0 & 24.0 & 6.0 & 32 \\
\hline & Wedges & $3^{\mathrm{c}}$ & 190 & 3.5 & 26.0 & 8.0 & 39 \\
\hline & Noisettes & $3^{\mathrm{c}}$ & 155 & 2.0 & 26.0 & 4.5 & 39 \\
\hline & Pancakes & $3^{\mathrm{c}}$ & 120 & 3.1 & 23.1 & 1.6 & 34 \\
\hline
\end{tabular}

${ }^{\mathrm{a}} \mathrm{DM}=$ Dry matter (before roasting/frying/microwaving)

${ }^{\mathrm{b}}$ Values mean

${ }^{\mathrm{c}}$ The same values

$n=$ The number of the same type of products

found, with satisfactory linearity $\left(\mathrm{R}^{2}=0.9997, n=6\right)$ over the range of $0.01-20 \mu \mathrm{g} / \mathrm{ml}$. This was used to calculate the amount of acrylamide in food samples. The detection limits (LOD) were calculated as $10 \mu \mathrm{g} / \mathrm{kg}$, which adequately determined the trace quantification of acrylamide in potato products. Both the repeatability and precision of the method were demonstrated by repetitive analyses, and calculating the average relative standard deviation (RSD) for the determination of concentration of acrylamide in ten one-batch samples of potato products. The quantitative analysis of potato products was in the concentration range of $380-451 \mu \mathrm{g} / \mathrm{kg}$ $(\mathrm{RSD}=4.5 \%, n=10)$ for acrylamide. The relative standard deviations (RSD) obtained for acrylamide were less than 5\%, which is a normal level in any food quality control and is usually satisfactory according to the Horwitz's formula for intra-laboratory analysis [23]. The mean recovery was $106 \%$. The recovery rate of the method was generally accepted for the determination of acrylamide in a variety of foods. This chromatographic procedure was applied to the determination of acrylamide concentration in the different potato products in this study.

\section{Reagents and Chemicals}

Acetonitrile, methanol, hexane and all other chemicals were of analytical grade and obtained from Sigma-Aldrich
(St. Louis, MO) and from Merck (Darmstadt, Germany). The acrylamide standard ( $\geq 99.8 \%$, catalogue No. 23701) was obtained from Sigma-Aldrich Chemical Company (USA). Stock standards were prepared in $80 \%$ methanol. The stock solution of acrylamide was $20,10,5.0,2.0,1.0,0.5$, $0.25,0.10,0.05,0.01 \mu \mathrm{g} / \mathrm{ml}$. All solutions were stored at $4{ }^{\circ} \mathrm{C}$ in glass light-resistant bottles.

The HPLC method for the determination of acrylamide was validated using the certified reference material (ERM-BD 273), which was supplied by the IRMM, (Belgium).

\section{Statistical Analysis}

Each experiment was comprised of three replications. The data were expressed as means \pm standard deviation. Statistical analysis was performed with the software package Statistica 9.0. Significant differences were calculated according to Duncan's Multiple range test at the 5\% level were considered statistically significant.

\section{Results and Discussion}

The purpose of this study was mainly to compare the effects of different domestic preparation methods of par-fried potato products such as pan-frying, and deep-frying, roasting and 
microwave treatment on the acrylamide formation. Acrylamide was found in all deep-frozen par-fried potato products before final preparation. The results obtained before final preparation of all samples are presented in Table 2. It was not surprising to note that the ready-to-eat frozen potato products, which were pre-prepared and pre-cooked, had a

Table 2 Acrylamide content of potato products before final preparation and after different domestic preparation methods

\begin{tabular}{|c|c|c|c|}
\hline \multirow[t]{2}{*}{ Product variety } & \multirow[t]{2}{*}{ Preparation methods } & \multicolumn{2}{|c|}{${ }^{\mathrm{A}}$ Acrylamide $(\mu \mathrm{g} / \mathrm{kg})$} \\
\hline & & $n$ & mean \\
\hline \multicolumn{4}{|c|}{ French fries } \\
\hline \multirow[t]{5}{*}{ Crinkle } & Before final preparation & 5 & $410 \pm 41$ \\
\hline & Pan-frying & & $535 \pm 49$ \\
\hline & Deep-frying & & $539 \pm 45$ \\
\hline & Roasting & & $660 \pm 51$ \\
\hline & Microwaving & & $744 \pm 72$ \\
\hline \multirow[t]{5}{*}{ Thick-cut, } & Before final preparation & 3 & $358 \pm 81$ \\
\hline & Pan-frying & & $527 \pm 39$ \\
\hline & Deep-frying & & $568 \pm 41$ \\
\hline & Roasting & & $704 \pm 68$ \\
\hline & Microwaving & & $763 \pm 55$ \\
\hline \multirow[t]{6}{*}{ Shoestring } & Before final preparation & 3 & $480 \pm 11$ \\
\hline & Pan-frying & & $622 \pm 10$ \\
\hline & Deep-frying & & $685 \pm 15$ \\
\hline & Roasting & & $817 \pm 17$ \\
\hline & Microwaving & & $863 \pm 25$ \\
\hline & Other potato products & & \\
\hline \multirow[t]{5}{*}{ Cubes } & Before final preparation & 3 & $188 \pm 10$ \\
\hline & Pan-frying & & $341 \pm 17$ \\
\hline & Deep-frying & & $392 \pm 18$ \\
\hline & Roasting & & $527 \pm 28$ \\
\hline & Microwaving & & $679 \pm 70$ \\
\hline \multirow[t]{5}{*}{ Wedges } & Before final preparation & 3 & $197 \pm 18$ \\
\hline & Pan-frying & & $436 \pm 18$ \\
\hline & Deep-frying & & $451 \pm 19$ \\
\hline & Roasting & & $588 \pm 22$ \\
\hline & Microwaving & & $635 \pm 30$ \\
\hline \multirow[t]{5}{*}{ Noisettes } & Before final preparation & 3 & $337 \pm 16$ \\
\hline & Pan-frying & & $387 \pm 19$ \\
\hline & Deep-frying & & $405 \pm 7$ \\
\hline & Roasting & & $547 \pm 9$ \\
\hline & Microwaving & & $696 \pm 12$ \\
\hline \multirow[t]{5}{*}{ Pancakes } & Before final preparation & 3 & $286 \pm 2$ \\
\hline & Pan-frying & & $437 \pm 11$ \\
\hline & Deep-frying & & $422 \pm 13$ \\
\hline & Roasting & & $564 \pm 10$ \\
\hline & Microwaving & & $694 \pm 11$ \\
\hline
\end{tabular}

A Mean \pm standard deviation, $n=$ The number of the same type of products certain acrylamide content. The mean level of acrylamide content in all frozen potato products before final preparation was found to be $322 \mu \mathrm{g} / \mathrm{kg}$, (Table 3). For the other-thanFrench-fry potato products, the acrylamide content was always lower $(252 \mu \mathrm{g} / \mathrm{kg})$ compared to French fries $(416 \mu \mathrm{g} / \mathrm{kg})($ Table 5). The shoestring French fries had the greatest concentration $(480 \mu \mathrm{g} / \mathrm{kg})$ and cubed potato products had the lowest $(188 \mu \mathrm{g} / \mathrm{kg})$ acrylamide content. All potato products contain a high level of acrylamide, probably caused by the initial heating process of the products. The differences observed in the acrylamide content of these par-fried products before final preparation at home suggests that manufacturers should optimize the production process for ready-to-eat frozen potato products. The latter should therefore be optimized for temperature, time and raw materials. In regards to raw materials, attention should be paid to acrylamide precursors and the quality of the potato.

The statistical analysis of the different types of French fries before final preparation showed no significant relationship between acrylamide content and the form and size of the French fries (Table 4). However, there was a significant difference between the form and size of other potato products (Table 4).

The effect of preparation methods, including time and temperature of processing, on the acrylamide content of the French fries and other-than-French-fries potato products was evaluated using a factorial design with two levels for conditions of processing (temperature/time), (Table 3) and four levels for domestic preparing methods (pan-frying, deep-frying, roasting, microwaving) (Table 5). Table 3 shows the effects of conditional processing on the acrylamide content of samples. Acrylamide content showed an increase as the temperature and time of processing increased. The acrylamide content of samples reached $482 \mu \mathrm{g} / \mathrm{kg}$ after preparing for $3 \mathrm{~min}$ at $180^{\circ} \mathrm{C}$ as opposed to $678 \mu \mathrm{g} / \mathrm{kg}$ after preparing for $10 \mathrm{~min}$ at $220{ }^{\circ} \mathrm{C}$. The statistical analysis showed significant differences $(P<0.05)$ in acrylamide content as a function of varieties for both conditions of processing. Many researchers have also reported that temperature and time processing were very important factors

Table 3 Statistical analysis for the effect of conditional processing (temperature/time) on the acrylamide content of potato products

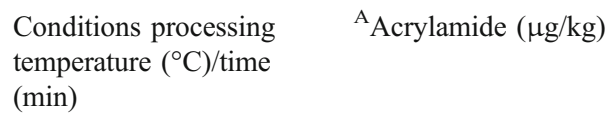

A Mean \pm standard deviation, B Pan-frying, C Deep-frying, D Roasting, E Microwaving, F All,

$\mathrm{a}, \mathrm{b}, \mathrm{c}-$ Mean in table followed by the same letter are not significantly different $(P \leq 0.05)$ 
Table 4 Statistical analysis for the effect of potato products type on acrylamide content

\begin{tabular}{llll}
\hline Type potato products & \multicolumn{3}{l}{${ }^{\mathrm{A}}$ Acrylamide $(\mu \mathrm{g} / \mathrm{kg})$} \\
\cline { 2 - 4 } & $n$ & Before final preparation & Preparing \\
\hline French fries & 11 & $416 \pm 61^{\mathrm{a}}$ & $669 \pm 68^{\mathrm{a}}$ \\
Crinkle & 5 & $410 \pm 41^{\mathrm{a}}$ & $620 \pm 101^{\mathrm{a}}$ \\
Thick-cut & 3 & $358 \pm 81^{\mathrm{a}}$ & $641 \pm 111^{\mathrm{a}}$ \\
Shoestring & 3 & $480 \pm 11^{\mathrm{a}}$ & $747 \pm 112^{\mathrm{a}}$ \\
Other potato products & 12 & $252 \pm 72^{\mathrm{b}}$ & $513 \pm 21^{\mathrm{b}}$ \\
Cubes & 3 & $188 \pm 10^{\mathrm{b}}$ & $485 \pm 151^{\mathrm{b}}$ \\
Wedges & 3 & $197 \pm 18^{\mathrm{b}}$ & $528 \pm 99^{\mathrm{b}}$ \\
Noisettes & 3 & $337 \pm 16^{\mathrm{c}}$ & $509 \pm 144^{\mathrm{b}}$ \\
Pancakes & 3 & $286 \pm 2^{\mathrm{d}}$ & $529 \pm 127^{\mathrm{b}}$ \\
\hline
\end{tabular}

A Mean \pm standard deviation, $\mathrm{a}, \mathrm{b}, \mathrm{c}, \mathrm{d}-$ Mean in columns followed by the same letter are not significantly different $(P \leq 0.05), n=$ The number of the same type of products

influencing the formation of acrylamide. The effect of hightemperature and long-time treatment of foods on acrylamide formation was investigated. It was found that these factors were responsible for a great decrease in AA levels in foods, without causing significant changes in the colour or texture parameters. In some previous studies, it was indicated that the temperature is required to be higher than $120{ }^{\circ} \mathrm{C}$ for the development of acrylamide. With reference to potato products, the suggested technological interventions for AA mitigation are relevant to pre-treatments as well as formulation and process changes [3-10, 24, 25].

The preparation methods under roasting were also lower in acrylamide content than the preparation methods under microwaving (Table 5). The highest acrylamide levels for French fries $(790 \mu \mathrm{g} / \mathrm{kg})$ and other-than- French-fries potato products $(676 \mu \mathrm{g} / \mathrm{kg})$ were found when these foods were treated with microwave radiation. The mean value of all samples $(725 \mu \mathrm{g} / \mathrm{kg})$ were higher than that of roasting $(630 \mu \mathrm{g} / \mathrm{kg})$, although both preparation methods used the

Table 5 Statistical analysis for the effect of preparation methods on the acrylamide content of potato products

\begin{tabular}{llll}
\hline Preparation methods & \multicolumn{2}{c}{ A Acrylamide $(\mu \mathrm{g} / \mathrm{kg})$} \\
\hline Before final preparation & ${ }^{\mathrm{B}} 416 \pm 61^{\mathrm{a}}$ & ${ }^{\mathrm{C}} 252 \pm 72^{\mathrm{a}}$ & $\mathrm{D}_{322 \pm 154^{\mathrm{a}}}$ \\
Pan-frying & ${ }^{\mathrm{B}} 561 \pm 53^{\mathrm{b}}$ & ${ }^{\mathrm{C}} 400 \pm 46^{\mathrm{b}}$ & $\mathrm{D}_{469 \pm 109^{\mathrm{b}}}$ \\
Deep-frying & ${ }^{\mathrm{B}} 597 \pm 67^{\mathrm{b}}$ & ${ }^{\mathrm{C}} 418 \pm 53^{\mathrm{b}}$ & ${ }^{\mathrm{D}} 495 \pm 114^{\mathrm{b}}$ \\
Roasting & $\mathrm{B}_{727 \pm 71^{\mathrm{c}}}$ & ${ }^{\mathrm{C}} 557 \pm 51^{\mathrm{c}}$ & ${ }^{\mathrm{D}} 630 \pm 100^{\mathrm{c}}$ \\
Microwaving & ${ }^{\mathrm{B}} 790 \pm 64^{\mathrm{d}}$ & ${ }^{\mathrm{C}} 676 \pm 59^{\mathrm{d}}$ & ${ }^{\mathrm{D}} 725 \pm 107^{\mathrm{d}}$ \\
\hline
\end{tabular}

A Mean \pm standard deviation, B French fries, $n=11$, C Other potato products, $n=12$, D All products, $n=23$,

$\mathrm{a}, \mathrm{b}, \mathrm{c}, \mathrm{d}-$ Mean in columns followed by the same letter are not significantly different $(P \leq 0.05)$ same conditions (time and temperature) (Tables 3 and 5). These results suggest that acrylamide is also produced in potato products under microwave heat processing just like conventional heating methods. Additionally, microwaving might be more favourable to the formation of acrylamide than conventional heating methods, such as roasting. Many studies have reported that various factors affected the reaction yields of acrylamide, such as the temperature, heating time, types of sugar compounds and water concentration [3-10]. Not only heating temperature and time, but also the modality of heat transfer are regarded to be important process factors influencing acrylamide formation. The heat processing method contributing to the formation of acrylamide should also be taken into consideration $[24,25]$. The microwave heating method is different than conventional heating. For conventional heating such as boiling, roasting or frying, heat transfer is mainly by convection and conduction or radiation. Microwaves offer a fast temperature rise in foods owing to their capacity to generate heat energy inside the food, without requiring any medium as a vehicle for heat transfer. The specific microwave effect, such as the effect of an electromagnetic field, acts directly on the polar molecules of the samples, causing the rotation or the liberation of chemical bonds, resulting in a weakening of the chemical bond, a lowering of the reaction energy and an acceleration of the chemical reaction. A low thermal conductivity product may quickly reach high temperatures which, does not occur in conventional heating. Microwave heating provides a favourable medium for the production of acrylamide and probably affects the formation and kinetics of acrylamide due to its extraordinary heating style. The present results suggest that the specific microwave effect could play a larger role than conventional heating in intensifying the formation of acrylamide. Other authors have also presented similar results. The studies have quantified a large amount of acrylamide $(551 \mu \mathrm{g} / \mathrm{kg})$ in microwave- heated grated potatoes, which was even higher than some potato samples under a frying treatment $(447 \mu \mathrm{g} / \mathrm{kg})$. Moreover, it was demonstrated that concentrations of acrylamide in potato baked after being precooked by the microwave pre-treatment were higher than those in the products baked without being pre-cooked. These results indicate that microwave heating might induce a high amount of acrylamide contaminant in foods [24, 25]. Therefore, there is a need for further studies on this issue. Moreover, it is necessary to consider a possible reduction of microwave heating in the processing of carbohydrate-rich food.

\section{Conclusions}

In conclusion, the discovery of acrylamide in commonlyheated foods has shaken consumer confidence in the quality and safety of thermally processed foods. Acrylamide is 
present in ready-to-eat food even before heat treatment in the home. This study demonstrated that acrylamide is present in all samples of ready-to-eat frozen potato products available in local supermarkets. Nowadays, reducing the acrylamide content of foods has become a major target for the food industry. Thus, the principal objective must be to try to reduce this compound which is formed during food production.

Our results show that the temperature and time of thermal processing of potato products are important factors in the formation of acrylamide. Therefore, the heat treatment parameters of the products during processing such as baking, frying, roasting, or microwaving in the home should be controlled and reduced as much as possible. Generally, the consumer is not aware of the actual oven temperature and this may differ from the temperature setting. Thus, there is a need for better temperaturecontrolled domestic ovens.

This study also demonstrated that, compared to conventional heating such as roasting, microwave treatment is more favourable for the formation of acrylamide in potato products under the same processing conditions (treatment time and temperature). Microwave heating has a marked effect on the formation of acrylamide. Therefore, the use of microwave heating for the thermal processing of carbohydrate-rich food should be limited as much as possible.

Open Access This article is distributed under the terms of the Creative Commons Attribution Noncommercial License which permits any noncommercial use, distribution, and reproduction in any medium, provided the original author(s) and source are credited.

\section{References}

1. IARC (International Agency for Research on Cancer) (1994) Acrylamide In IARC Monographs on the Evaluation of Carcinogenic Risk to Humans 60: 389-433, IARC, Lyon, France

2. WHO (1996) Acrylamide In: Guidelines for Drinking-Water Quality, 2nd ed. 2: 541-547 Health criteria and other supporting information. International Programme on Chemical Safety, World Health Organization, Geneva, Switzerland

3. WHO (2002) FAO/WHO Consultation on the Health Implications of Acrylamide in Food. Summary Report. Geneva, Switzerland, June 25-27, 2002

4. Granda C, Moreira R, Tichy S (2004) Reduction of acrylamide formation in potato chips by low-temperature vacuum frying. $\mathrm{J}$ Food Sci 69:E405-E411. doi:10.1111/j.1365-2621.2004.tb09903.x

5. Matthäus B, Haase NU, Vosmann K (2004) Factors affecting the concentration of acrylamide during deep-fat frying of potatoes. Eur J Lipid Sci Tech 106:793-801
6. Claeys WL, De Vleeschouwer K, Hendrickx ME (2005) Quantifying the formation of carcinogens during food processing: Acrylamide. Trends Food Sci Tech 16:181-193

7. Gökmen V, Palazoğlu TK, Şenyuva HZ (2006) Relation between the acrylamide formation and time-temperature history of surface and core regions of French fries. J Food Eng 77:972-976

8. Viklund G, Mendoza F, Sjöholm I, Skog K (2007) An experimental set-up for studying acrylamide formation in potato crisps. Lebensm Wiss Technol 40:1066-1071

9. Skog K, Viklund G, Olsson K, Sjöholm I (2008) Acrylamide in home-prepared roasted potatoes. Mol Nutr Food Res 52:307-312

10. Gökmen V, Palazoğlu TK (2008) Acrylamide formation in foods during thermal processing with a focus on frying. Food Bioprocess Tech 1:35-42

11. Mestdagh F, De Wilde T, Castelein P, Németh O, Van Peteghem C, Meulenaer B (2008) Impact of the reducing sugars on the relationship between acrylamide and Maillard browning in French fries. Eur Food Res Tech 227:69-76

12. Misra A, Kulshrestha K (2003) Effect of storage on nutritional value of potato flour made from three potato varieties. Plant Food Hum Nutr 58:1-10

13. AOAC (1990) Official Methods of Analysis. Gaithersburg, MD: Association of Official Analytical Chemists, Moisture in animal feed, Official Methods of Analysis 930.15 Gaithersburg, MD: AOAC

14. Barber DS, Hunt J, LoPachin RM, Ehrich M (2001) Determination of acrylamide and glycidamide in rat plasma by reversed-phase high performance liquid chromatography. J Chromatogr B 758:289-293

15. Zhang Y, Zhang G, Zhang Y (2005) Occurrence and analytical methods of acrylamide in heat- treated foods. Review and recent developments. J Chromatogr A 1075:1-21

16. Gökmen V, Șenyuva HZ, Acar J, Sarioğlu K (2005) Determination of acrylamide in potato chips and crisps by high - performance liquid chromatography. J Chromatogr A 1088:193-199

17. Gökmen V, Șenyuva HZ (2006) A generic method for determination of acrylamide in thermally processed foods. J Chromatogr A 1120:194-198

18. Wang H, Lee AWM, Shuang S, Choi MMF (2008) SPE/HPLC/ UV studies on acrylamide in deep-fried flour-based indigenous Chinese foods. Microchem J 89:90-97

19. Wenzl T, Calle MB, Anklam E (2003) Analytical methods for determination of acrylamide in food products: A review. Food Addit Contam 20(10):885-902

20. Hoenicke K, Gatermann R, Harder W, Hartig L (2004) Analysis of acrylamide in different foodstuffs using liquid chromatography tandem mass spectrometry and gas chromatography - tandem mass spectrometry. Anal Chim Acta 520:207-215

21. Nielsen J, Granby K, Hedegaard RV, Skibsted LH (2006) A liquid chromatography - tandem mass spectrometry method for simultaneous analysis of acrylamide and the precursors, asparagines and reducing sugars in bread. Anal Chim Acta 557:211-220

22. Peterson EV, Rosen J, Turner C, Danielsson R, Hellenas KE (2006) Critical factors and pitfalls affecting the extraction of acrylamide from foods: An optimization study. Anal Chim Acta 557:287-295

23. Horwitz W, Britton P, Stuart JC (1998) A simple method for evaluating data from an interlaboratory study. J AOAC Int 81:1257-1265

24. Yuan Y, Chen E, Zhao GH, Liu J, Zhang X, Hu ZS (2007) A comparative study of acrylamide formation induced by microwave and conventional heating methods. J Food Sci 72(4):212-216

25. Zhang Y, Fang H, Zhang Y (2008) Study of formation of acrylamide in asparagine-sugar microwave heating systems using UPLC-MS/MS analytical method. Food Chem 108:542-550 